\title{
Recollection
}

\section{A successful international cooperation with a bumpy start}

\section{Ming Li}

Beijing Institutes of Life Science, Chinese Academy of Sciences, Beijing 100101, China

Science has no boarders. The saying could not be more accurate in the case of infectious disease research. It is publicly known that infectious diseases can travel, not only through infected people, animals or insects, but also by commercial shipments. In the era of globalization, it is not possible to fight infectious diseases in one nation without worrying about what is happening elsewhere in the world. Emerging and re-emerging infectious diseases such as the outbreak of SARS in 2003 are likely to panic the Asian society at any time. To fight these diseases, the Chinese Academy of Sciences (CAS) and the University of Tokyo (UT) launched China-Japan Collaboration on Emerging and Re-emerging Infectious Diseases in 2005, as part of the Program of Founding Research Centers for Emerging and Re-emerging Infectious Diseases supported by Japan Ministry of Education, Science, Sports and Technology (MEXT).

China and Japan has a long history of collaborating in science and technology, yet the earlier collaboration was quite simple, and mostly involved sending Chinese students and young scientists to Japan for scientific training. Later on, along with the tremendous progress China made in S\&T, the China-Japan scientific cooperation has become more mutual and versatile. However, in the field of life science, most of the collaborations are between individual Chinese and Japanese scientists and relatively "small-scaled". Doubtless to say, the CAS-UT collaboration on emerging and re-emerging infectious diseases has taken the China-Japan collaboration in life science to a whole new level.

Supported by a contract fund from Japan's MEXT, the Institute of Medical Science of UT (IMSUT) has established two joint laboratories in the Institute of Microbiology (IM) and the Institute of Biophysics (IBP) of CAS, with one lab focusing on molecular immunology and molecular microbiology and the other focusing on structural virology and immunology (Fig. 1).

In the past five years, the Japanese side has sent five

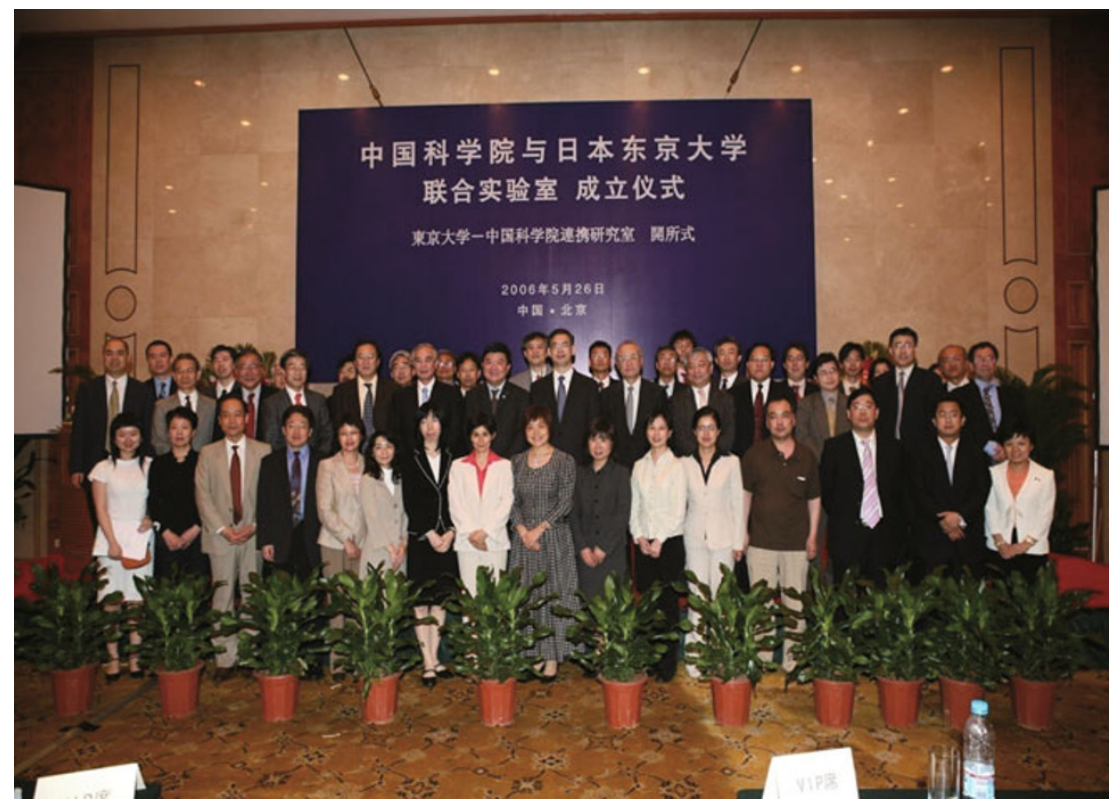

Figure 1. Opening Ceremony of the Chinese Academy of Sciences and the University of Tyoko Joint Laboratories 
Japanese scientists to do research at the joint labs in China. At the same time, several Chinese scientists have been working at the labs in Japan. Based on the two joint laboratories, the collaboration has been extended to some Chinese hospitals such as Beijing Di Tan Hospital, as well as China CDC. The two joint laboratories, recognized in 2006 by both Japan's MEXT and China's Ministry of Science and Technology (MOST) as Sino-Japan Intergovernmental S\&T Collaboration Projects, have effectively promoted and facilitated research collaboration in the fields of microbiology, immunology and epidemiology between the two sides. After five years of successful run of the joint labs, in 2010, the CAS and the UT made a joint commitment to collaborate for a further five years (Fig. 2) and the collaboration has since been expanded to a broader area of life science (Fig. 3).

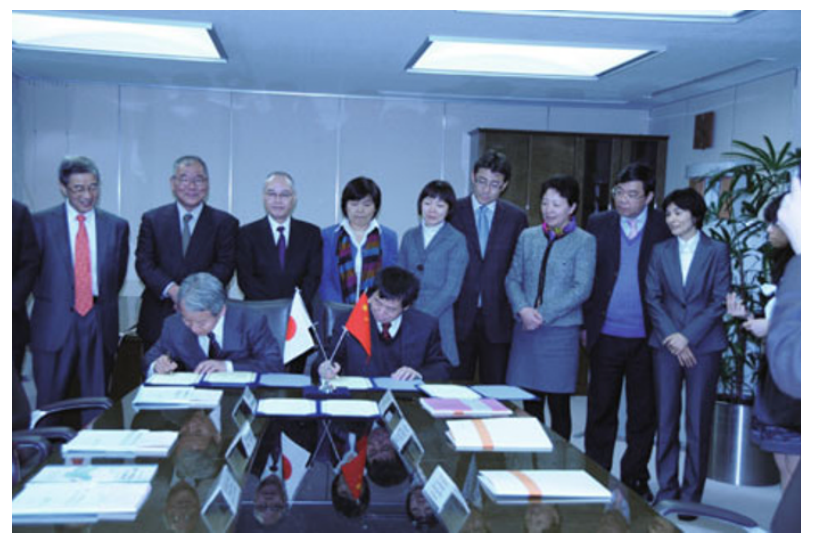

Figure 2. CAS Vice President Jiayang Li (front right) and UT Vice President Akihiko Tanaka (front left) signing a new agreement to continue the collaboration

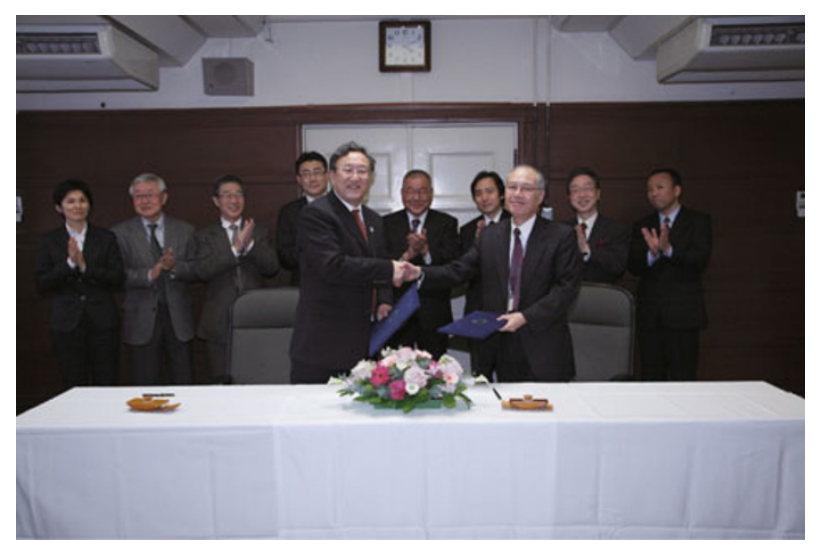

Figure 3. Beijing Institutes of Life Science (BIOLS, CAS) President Le Kang (front left) and IMSUT Dean Motoharu Seiki (front right) signing an agreement to collaborate in various areas of life science

The cooperation turns out to be such a success that in 2010 , one of the key persons who initiated the project,
Professor Aikichi Iwamoto from IMSUT, won the CAS Award for International Cooperation in Science and Technology (Fig. 4). Later, he was granted the 2011 Friendship Award of China, and recently nominated as a candidate for the 2011 China International Science and Technology Cooperation Award, China's highest and most esteemed honor for foreign scientists.

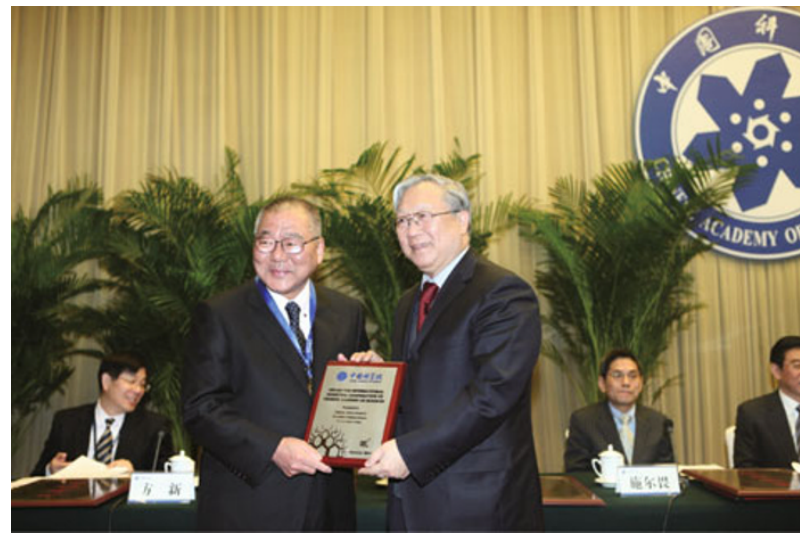

Figure 4. Prof. Aikichi Iwamoto (left) was granted the 2010 CAS Award for International Cooperation in Science and Technology by CAS President Yongxiang Lu (right)

However, such a successful collaboration did not necessarily have a smooth start. Under the international circumstances in 2005, it might not be the perfect time for CAS to start a big cooperation with UT. Nevertheless, the CAS still decided to push ahead on the collaboration and invited UT President Hiroshi Komiyama to China for the launching ceremony of the China-Japan Collaboration on Emerging and Re-emerging Infectious Diseases in April 2005. Meantime, President Komiyama was also bestowed the title of honorary professor during his visit to Beijing (Fig. 5). After the

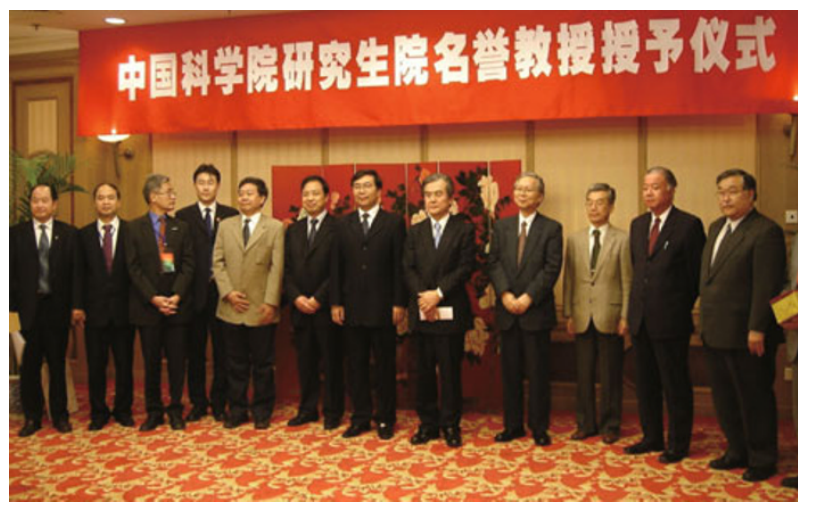

Figure 5. CAS Executive Vice President (now CAS President) Chunli Bai (sixth from right) conferred the certificate of honorary professorship to Prof. Hiroshi Komiyama (fifth from right) 
ceremony, President Komiyama said, 'Before I came here, a lot of people advised me to cancel or postpone my visit. But I firmly believed that the cooperation and exchanges between Chinese and Japanese scientists have been going on for decades, and that the long-term friendship between us won't be affected by some short-term events.' Well, time tells everything. After six years, the academic friendship between CAS and UT is stronger than ever. And the cooperation between CAS and UT will continuously bring Chinese and Japanese scientists together to face scientific challenges, and help strengthen the Sino-Japanese friendship in the long run. 